\title{
Article \\ Contributions to Modeling, Simulation and Controlling of a Pumping System Powered by a Wind Energy Conversion System
}

\author{
Dorin Bordeașu $^{1, *}$, Octavian Proștean ${ }^{1}$ (D) and Cornel Hatiegan ${ }^{2, *}$ \\ 1 Department of Automation and Applied Informatics, Faculty of Automation and Computing, \\ Polytechnic University of Timisoara, 300006 Timisoara, Romania; octavian.prostean@upt.ro \\ 2 Department of Engineering Sciences, Faculty of Engineering, Babeș-Bolyai University, \\ 400084 Cluj-Napoca, Romania \\ * Correspondence: bordeasu.dorin@gmail.com (D.B.); cornel.hatiegan@ubbcluj.ro (C.H.); \\ Tel.: +40-771-457-276 (D.B.)
}

check for updates

Citation: Bordeașu, D.; Proștean, O.; Hatiegan, C. Contributions to Modeling, Simulation and Controlling of a Pumping System Powered by a Wind Energy Conversion System. Energies 2021, 14 7696. https://doi.org/10.3390/ en14227696

Academic Editors: Valery Okulov and Tomonobu Senjyu

Received: 14 October 2021

Accepted: 12 November 2021

Published: 17 November 2021

Publisher's Note: MDPI stays neutral with regard to jurisdictional claims in published maps and institutional affiliations.

Copyright: (c) 2021 by the authors. Licensee MDPI, Basel, Switzerland. This article is an open access article distributed under the terms and conditions of the Creative Commons Attribution (CC BY) license (https:// creativecommons.org/licenses/by/ $4.0 /)$.

\begin{abstract}
At present, the energy consumption of the pumping unit represents the highest cost in operating a pumping system. Due to this reason, this paper proposes a reliable and robust solution for integrating a wind energy conversion system (WECS) into an already existing pumping system (PS), without being overly intrusive for the PS, and without altering the control strategy or the hardware of the commercial WECS. The current work begins by presenting the modeling undertaken, which includes a WECS with pitchable blades, a doubly-fed induction generator (DFIG) together with its power converter, a centrifugal pump, an induction motor (IM) with its power converter, and an irrigation network with a pressure transducer. The second part consists of the proposed three-level controller: a general controller that regulates the WECS power demand according to the pumping pressure reference; three second-level controllers; two necessary for the WECS and one for the PS; and three first level controllers, two for controlling the power converters of the WECS generator and one for controlling the pump motor power converter. Finally, the simulation results of the proposed system control strategy are presented, showing its technical feasibility and good performance.
\end{abstract}

Keywords: pumping system; wind energy conversion system; cascade pi controller; pressure controller; maximum power point tracking; vector controller; variable frequency controller; modeling and simulation

\section{Introduction}

Irrigation systems have evolved significantly in recent years through progressive modernization (from traditional irrigation by gravitation to sprinklers and drip irrigation systems), increasing water usage efficiency. As a result of the solutions with high water usage efficiency, the electricity consumption of pumping systems (PS) has increased drastically. Currently, the PS for irrigating agricultural fields are supplied with electricity from the national grid in areas where this grid can be reached, and mostly by gasoline or diesel electric generators where it cannot be reached. Few PS are powered by renewable energy sources (RES), most of which are powered by photovoltaic (PV) generators [1] because they are used during the summer, with maximum demand on the hottest and sunniest days of the year, and photovoltaic systems (PVS) produce most of the energy exactly during this period [2]. A reliable alternative is presented by PS powered by a wind energy conversion system (WECS) which, depending on the characteristics of the wind at the site, can ensure the availability of energy even during the night and on cloudy days.

Due to the current favorable legislation, coupled with the continuing decline in wind energy prices, the agricultural sector is considering the installation of PS powered by a WECS. Despite the economic profitability offered by wind-powered pumping installations and the continuous growth in the market demand [1,3], there is still no indus- 
trial/commercial solution designed for irrigation purposes (pumping water at constant pressure). Most of the PS powered by a WECS [4-6] are designed only for energy storage (pumping water at variable flow and pressure in a water storage).

Given the above, the current paper proposes a reliable and robust solution for modeling and controlling a high-power PS powered by a WECS with industrial applicability. Compared to other related work [7-10], the current paper has more industrial applicability, because it consists of integrating a commercial WECS, without altering its hardware or controller, into an existing pumping system. Most of the WECS manufacturers are not open to changing/adjusting their current control strategies, for full and perfect integration within an irrigation PS, because such a change/adjustment represents a significant cost, and the WECS manufacturers do not believe the current market for a PS that requires a WECS is large enough to pay this cost.

\section{Mathematical Modeling}

The modeling mainly considered the wind energy conversion system (WECS, containing: an aeroelastic model of a three-blade horizontal axis wind turbine based on lookup tables for the aerodynamics (power and thrust coefficients, CP and CT) [11,12]; a 3rd-order drive train model; an alpha-beta $(\alpha-\beta)$ representation of the doubly-fed induction generator (DFIG) together with the back-to-back converter; a 1st-order pitch actuator; and a 2nd order tower model) and the pumping system (containing the variable frequency drive, induction motor (IM), the pump, water distribution, and irrigation systems) (Figure 1). The dynamics of the other systems were either ignored or indirectly transferred to the already modeled systems.

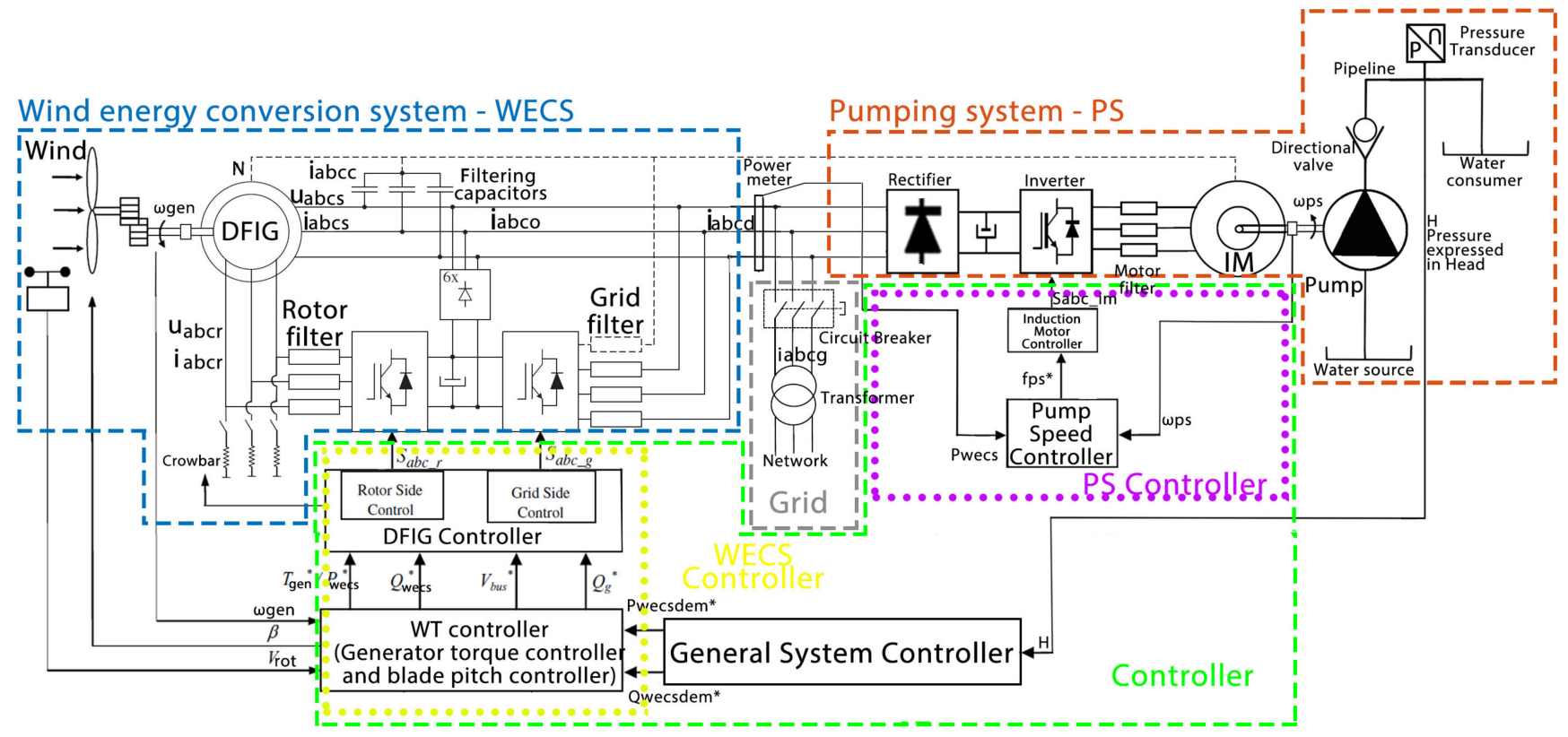

Figure 1. Proposed PS powered by the WECS control structure.

\subsection{WECS Modeling}

The inputs required by the WECS model are the average wind speed over the rotor area $v_{\text {rot }}$ (effective wind speed) and the power demand $P_{\text {wecsdem }}$ reference supplied by the general controller. The outputs available from the WECS model are the generated power $P_{\text {wecs }}$, and three phases of AC voltages and currents. 


\subsubsection{Wind Turbine Modeling}

The wind speed acting on the wind turbine (WT) rotor $v_{\text {rot }}[11,12]$ represents the incoming wind speed in front of the rotor $v$ minus the nacelle velocity $\dot{z}$ resulted from the tower deflection Equation (13):

$$
v_{\text {rot }}=v-\dot{z}
$$

The relation between the wind speed acting on the WT rotor $v_{\text {rot }}$ and the rotor angular velocity $\omega_{w t}$ is given by the tip speed ratio $\lambda(2)$, where $R$ is the WT rotor radius [11-13]:

$$
\lambda=\frac{R \cdot \omega_{w t}}{v_{r o t}}
$$

The WT rotor torque $T_{w t}$ and thrust force $F_{w t}$ are obtained with the help of the following two static relationships (3) and (4) [11,12]:

$$
\begin{gathered}
T_{w t}=\frac{1}{2} \cdot\left(v_{\text {rot }}\right)^{3} \cdot \rho_{\text {air }} \cdot A_{w t} \cdot C_{p}(\lambda, \beta) \cdot\left(\omega_{w t}\right)^{-1} \\
F_{w t}=\frac{1}{2} \cdot\left(v_{\text {rot }}\right)^{2} \cdot \rho_{\text {air }} \cdot A_{w t} \cdot C_{T}(\lambda, \beta)
\end{gathered}
$$

where $\rho_{a i r}$ is the average air density around the rotor, $A_{w t}$ is the disc area of the wind turbine rotor, and $C_{P}$ and $C_{T}$ are two look-up tables derived from the geometry of the blades as functions of tip speed ratio $\lambda$ and blade pitching angle $\beta$.

\subsubsection{Drive Train Modeling}

The generator torque $T_{\text {gen }}$ and speed $\omega_{\text {gen }}$ are calculated using a 3rd-order drive train model [14], representing the two rotating shafts (with $I_{w t}$ representing the WT rotor inertia and $I_{g e n}$ the generator inertia), connected through a gearbox with $\varphi$ being the shaft torsion angle, $K_{\text {shaft }}$ the torsion spring constant, $B_{\text {shaft }}$ the viscous friction, $N$ the gear ratio, and $p_{\text {gen }}$ the number of generator poles.

$$
\begin{gathered}
I_{w t} \cdot \dot{\omega_{w t}}=T_{w t}-K_{\text {shaft }} \cdot \varphi-B_{\text {sfhat }} \cdot \dot{\varphi} \\
I_{g e n} \cdot\left(\frac{2}{p_{g e n}}\right) \cdot \dot{\omega}_{g e n}=\frac{K_{\text {shaft }}}{N} \cdot \varphi+\frac{B_{\text {sfhat }}}{N} \cdot \dot{\varphi}-T_{\text {gen }} \\
\dot{\varphi}=\omega_{w t}-\frac{\omega_{g e n}}{N}
\end{gathered}
$$

\subsubsection{DFIG—Doubly Fed Induction Generator Modeling}

The stator ${\overrightarrow{i_{\text {dfig.s }}}}^{\mathrm{s}}$ and rotor ${\overrightarrow{i_{\text {dfig. }}}}^{\mathrm{s}}$ current vectors of the WECS DFIG are obtained using the electromagnetic Equations (8)-(10) [15] (pp. 216-217) of an induction machine in the stator reference frame $(\alpha, \beta)$ operating in generator mode $\left(T_{\text {gen }} \leq 0\right)$ [16] (Figure 2).

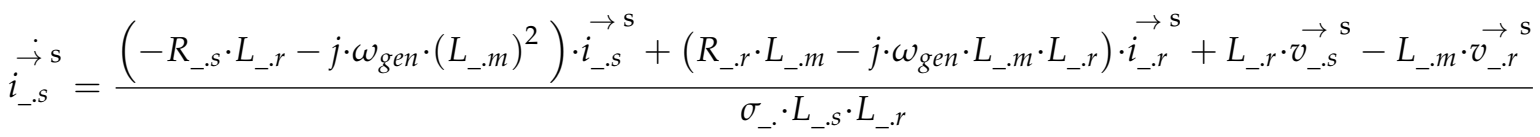

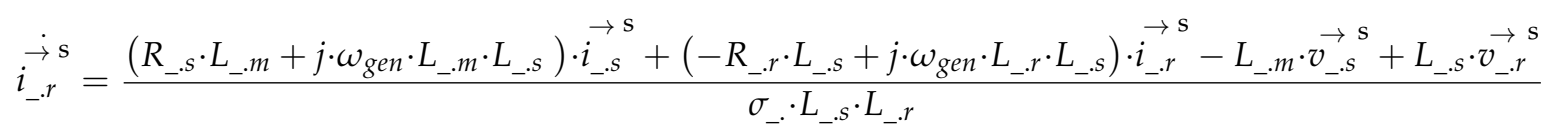

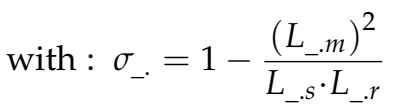



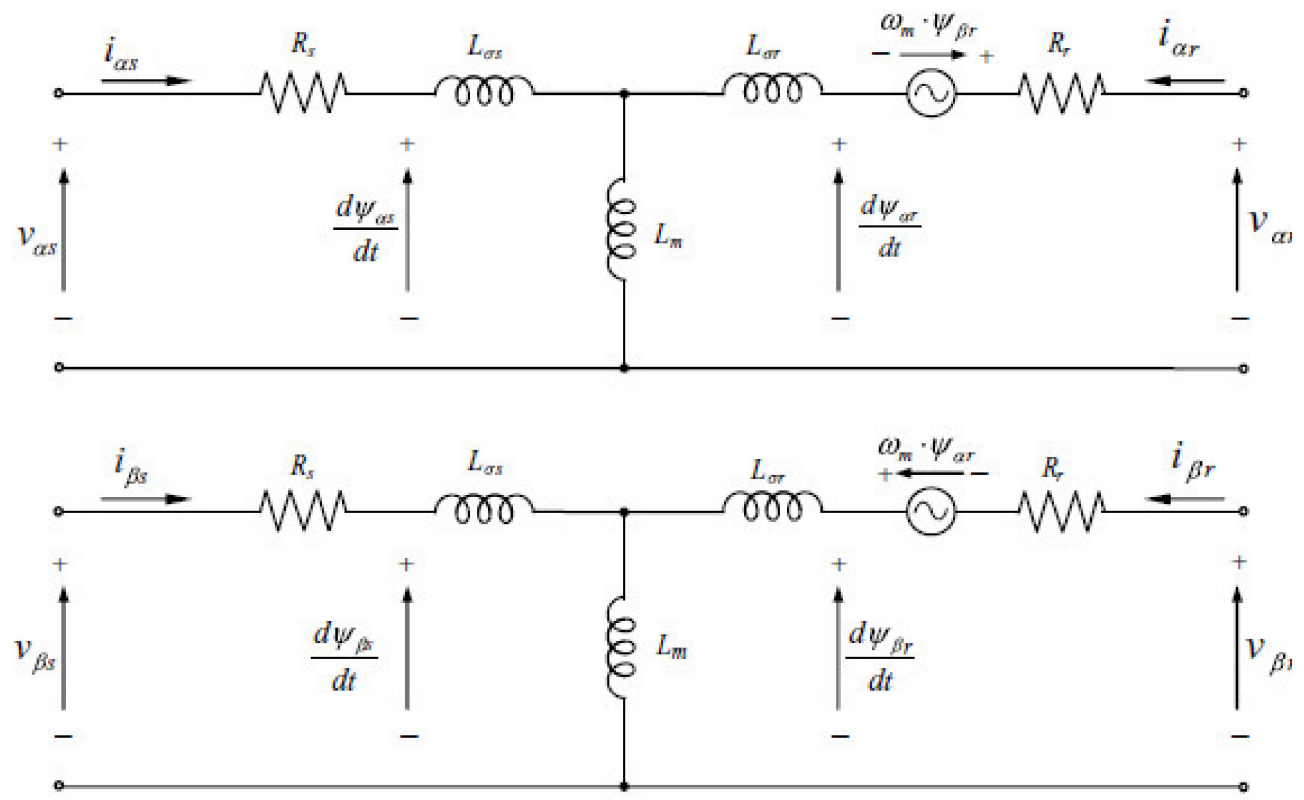

Figure 2. DFIG model (equivalent circuit) in the $\alpha$ - $\beta$ reference frame [17] (p. 278).

In Equations (8)-(10), "_" stands for DFIG or IM depending on which the Equations refer to. Where $\omega_{\text {gen }}$ is the DFIG rotor speed (and the in case that Equations (8)-(10) refer to IM), then $\omega_{\text {gen }}$ should be substituted with $\omega_{p s,}, \overrightarrow{v_{-} s} \mathrm{~s}$ and $\overrightarrow{v_{-} .} \mathrm{s}$ are the DFIG/IM stator and rotor voltage vectors, $R_{-} . s$ and $R \_. r$ represent the DFIG/IM stator and rotor resistance, and $L_{-} \cdot m$, $L_{-} \cdot s$, and $L_{-} \cdot r$ are the DFIG/IM magnetizing, stator, and rotor inductances, respectively.

The electromagnetic torque of the generator $T_{\text {gen }}$ and the generated electrical power $P_{\text {wecs }}$ are calculated using the following Equations (11) and (12) [15] (p. 214):

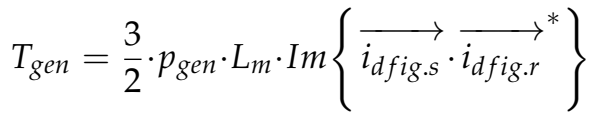

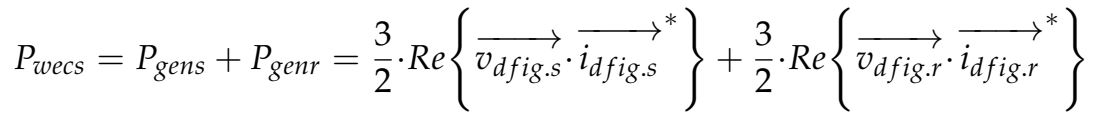

where $p_{\text {gen }}$ represents the generator number of pole pairs, $P_{\text {gens }}$ represents the power delivered by the DFIG stator, and $P_{\text {genr }}$ represents the power delivered by the DFIG rotor.

\subsubsection{Tower}

The tower dynamics are represented by a mass-spring-damper system where $z, \dot{z}, \ddot{z}$ represents the deflection, speed, and acceleration of the tower top, respectively [11,12]:

$$
m_{\text {wecs }} \cdot \ddot{z}=F_{w t}-4 \cdot \pi \cdot m_{\text {wecs }} \cdot\left(f_{\text {ntow }}\right)^{2} \cdot z-4 \cdot \pi \cdot m_{\text {wecs }} \cdot f_{\text {ntow }} \cdot \zeta_{\text {tow }} \cdot \dot{z}
$$

In Equation (13), $m_{\text {wecs }}$ represents the WECS mass (including the tower mass), and $\zeta_{\text {tow }}$ and $f_{\text {ntow }}$ represent the tower damping ratio and first eigenfrequency, respectively.

\subsubsection{Pitch Actuator}

The dynamics of the pitch actuator are modeled using Equation (14) as a second-order system with a time constant $\tau_{\beta}$ and an input delay $\lambda_{\beta}$ from input $\mathrm{u}_{\beta}$ to the pitch rate $\dot{\beta}$ [14].

$$
\ddot{\beta}=\frac{1}{\tau_{\beta}}\left(u_{\beta}^{\lambda}-\dot{\beta}\right)
$$


The pitch actuator is controlled by a proportional regulator with constant $K_{\beta}$ (15) [14]:

$$
u_{\beta}=K_{\beta}\left(\beta_{r e f}-\beta\right)
$$

where $\beta_{\text {ref }}$ represents the pitch angle reference.

\subsection{Pumping System Modeling}

The dynamics of the PS, including the water distribution and irrigation systems, are modeled according to the following equation of motion based on the difference between the pump (load) and motor (electromechanical) torques ( $T_{\text {pump }}$ and $\left.T_{\text {motor }}\right)[7,18]$ :

$$
I_{p s} \cdot \dot{\omega}_{p s}=T_{m o t o r}-T_{p u m p}
$$

where $I_{p s}$ is the moment of inertia of the pumping system, $\omega_{p s}$ is the angular velocity of the shaft connecting the motor and pump, $T_{\text {motor }}$ is the electromechanical torque of the motor, and $T_{\text {pump }}$ is the pump (motor load) torque.

\subsubsection{IM (Induction Motor) Modeling}

Similar to the DFIG, the electromagnetic torque of the IM $T_{\text {motor }}$ is calculated according to Equation (17) [15] (p. 146), where the IM stator ${\overrightarrow{i_{i m . s}}}^{\mathrm{s}}$ and rotor ${\overrightarrow{i_{\text {im.r. }}}}^{\mathrm{s}}$ current space vectors are obtained based on a model using the same electromagnetic Equations (8)-(10) of an induction machine in the stator reference frame $(\alpha, \beta)$, but this time operating in motor mode $\left(T_{\text {motor }} \geq 0\right)$

$$
T_{\text {motor }}=\frac{3}{2} \cdot p_{\text {motor }} \cdot L_{i m \cdot m} \cdot \operatorname{Im}\left\{\overrightarrow{i_{i m . s}} \cdot{\overrightarrow{i_{i m . r}}}^{*}\right\}
$$

where $p_{\text {motor }}$ represents the motor number of pole pairs and $L_{i m . m}$ represents the motor magnetizing inductance.

\subsubsection{Variable Speed Centrifugal Pump}

The pump is modeled based on $\mathrm{A}, \mathrm{B}$, and $\mathrm{C}$ coefficients identified through quadratic regression (18) from the centrifugal pump characteristic head-flow $\left(H_{0}-Q_{0}\right)$ curve, and on $\mathrm{D}$ and $E$ coefficients also identified through quadratic regression (19) from the efficiency-flow $\left(\eta_{0}-Q_{0}\right)$ curve. Both curves $\left(H_{0}-Q_{0}\right.$ and $\left.\eta_{0}-Q_{0}\right)$ are at nominal speed $\left(\omega_{p s 0}\right)[4,19,20]$. Starting from Equation (18), until Equation (34), including Equations (48)-(52), the subscript " 0 " stands for the nominal value, and " $s$ " for the current value.

$$
\begin{gathered}
H_{0}=A+B \cdot Q_{0}+C \cdot\left(Q_{0}\right)^{2} \\
\eta_{0}=D \cdot Q_{0}+E \cdot\left(Q_{0}\right)^{2}
\end{gathered}
$$

where $H$ represents the pump head, $Q$ the pump flow, and $\eta$ the pump efficiency.

The response of the centrifugal pump to a different speed is modeled using the pump affinity laws (in the current work, the change in water density $\rho_{w s}=\rho_{w 0}$ and pump geometry $G_{s}=G_{0}$ during the speed variation is ignored) [21] (p. 776):

$$
\frac{\mathrm{Q}_{\mathrm{s}}}{Q_{0}}=\frac{\omega_{p s s}}{\omega_{p s 0}} \cdot\left(\frac{G_{s}}{G_{0}}\right)^{3} ; \frac{H_{s}}{H_{0}}=\left(\frac{\omega_{p s s}}{\omega_{p s 0}}\right)^{2} \cdot\left(\frac{G_{s}}{G_{0}}\right)^{2} ; \frac{P_{\mathrm{pss}}}{P_{p s 0}}=\left(\frac{\rho_{w s}}{\rho_{w 0}}\right) \cdot\left(\frac{\omega_{p s s}}{\omega_{p s 0}}\right)^{3} \cdot\left(\frac{G_{s}}{G_{0}}\right)^{5} ;
$$

where $P_{p s}$ stands for the pumping system power consumption. 
By combining the $\left(H_{0}-Q_{0}\right)$ quadratic regression Equation (17) at nominal speed $\left(\omega_{p s 0}\right)$ with the pump affinity laws (20), the pump characteristic $\left(H_{s}-Q_{s}\right)$ as a function of pump speed is obtained (21):

$$
H_{s}=\left(\frac{\omega_{p s s}}{\omega_{p s 0}}\right)^{2} \cdot A+\left(\frac{\omega_{p s s}}{\omega_{p s 0}}\right) \cdot B \cdot Q_{s}+C \cdot\left(Q_{s}\right)^{2}
$$

Figure 3 shows the pump characteristic $\left(H_{s}-Q_{s}\right)$ curve at different speeds (frequency variation from 5 to $50 \mathrm{~Hz}$ ).

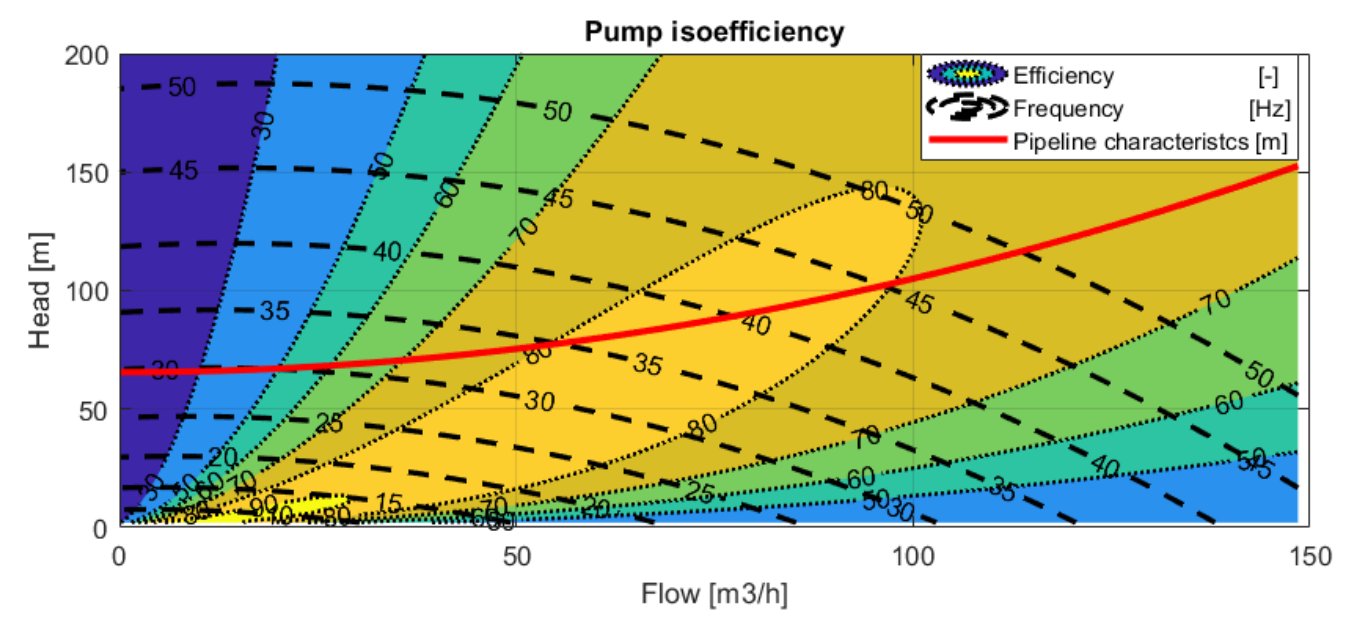

Figure 3. Pump iso-efficiency curve $\left(H_{s}-Q_{s}-\eta_{s}\right)$.

By combining the $\left(\eta_{0}-Q_{0}\right)$ quadratic regression of Equation (19) at nominal speed $\left(\omega_{p s 0}\right)$ with the pump affinity laws (20) using the equation from reference [20], the pump efficiency as a function of pump speed is obtained (22):

$$
\eta_{s}\left(\omega_{s}\right)=1-\left(1-\eta_{0}\right) \cdot\left(\frac{\omega_{p s 0}}{\omega_{p s s}}\right)^{0.1}=1-\left(\frac{\omega_{p s 0}}{\omega_{p s s}}\right)^{0.1}+D \cdot Q_{s} \cdot\left(\frac{\omega_{p s 0}}{\omega_{p s s}}\right)^{1.1}+E \cdot\left(Q_{s}\right)^{2} \cdot\left(\frac{\omega_{p s 0}}{\omega_{p s s}}\right)^{2.1}
$$

\subsubsection{Water Distribution and Irrigation System}

The water distribution and irrigation system characteristic curve is expressed by equation using [19]:

$$
H_{s}=H_{g}+k \cdot\left(Q_{s}\right)^{2}
$$

where $H_{g}$ is the static head, $Q_{s}$ is the system flow rate, and $k$ is the head loss coefficient. Figure 3 shows the iso-efficiency diagram of the pump together with the system characteristic curve. The IM pump used for the simulation can be found in reference [22].

The delivered flow as a function of pump speed $\left(\omega_{p s}\right)$ is given by the pump operating point, represented by the cross-point of the pump characteristic as a function of speed (21) with the system characteristic curve (23):

$$
H_{g}+k \cdot\left(Q_{s}\right)^{2}=\left(\frac{\omega_{p s s}}{\omega_{p s 0}}\right)^{2} \cdot \mathrm{A}+\left(\frac{\omega_{p s s}}{\omega_{p s 0}}\right) \cdot \mathrm{B} \cdot \mathrm{Q}_{\mathrm{s}}+C \cdot\left(Q_{s}\right)^{2}
$$

From which results:

$$
Q_{s}\left(\omega_{p s s}\right)=\frac{-\left(\frac{\omega_{p s s}}{\omega_{p s 0}}\right) \cdot \mathrm{B}-\sqrt{\left(\frac{\omega_{p s s}}{\omega_{p s 0}}\right)^{2} \cdot \mathrm{B}^{2}-4 \cdot\left[\left(\frac{\omega_{p s s}}{\omega_{p s 0}}\right)^{2} \cdot \mathrm{A}-\mathrm{H}_{\mathrm{g}}\right] \cdot(C-k)}}{2 \cdot(C-k)}
$$


The pump torque $\left(T_{\text {pump }}\right)$ is calculated based on the division of the delivered hydraulic power $\left(P_{\text {hydraulic }}\right)$ with the pump speed $\left(\omega_{p s s}\right)$, taking into consideration the pump efficiency at the operating point $\left(\eta_{s}\right)$, Equation (26) [23]:

$$
T_{\text {pump }}=\frac{P_{\text {pump }}}{\omega_{p s s}}=\frac{P_{\text {hydraulic }}}{\omega_{p s s} \cdot \eta_{s}}=\frac{\rho_{w} \cdot g \cdot H_{s} \cdot Q_{s}}{\omega_{p s s} \cdot \eta_{s}}
$$

where $\rho_{w}$ is the water density and $g$ is the gravitational acceleration.

Finally, the pump torque as function pump speed, can be obtained through the substitution of Equations (22), (23), and (25) into Equation (26):

$$
T_{\text {pump }}=\frac{\rho_{w} \cdot g \cdot H_{g} \cdot Q_{s}+\rho \cdot g \cdot k_{1} \cdot\left(Q_{s}\left(\omega_{p s s}\right)\right)^{3}}{\omega_{p s s} \cdot\left(1-\left(\frac{\omega_{p s 0}}{\omega_{p s s}}\right)^{0.1}+D \cdot Q_{s}\left(\omega_{p s s}\right) \cdot\left(\frac{\omega_{p s 0} 0}{\omega_{p s s}}\right)^{1.1}+E \cdot\left(Q_{s}\left(\omega_{p s s}\right)\right)^{2} \cdot\left(\frac{\omega_{p s 0}}{\omega_{p s s}}\right)^{2.1}\right)}
$$

\section{Control Strategy}

The control strategy of the PS powered by a WECS was developed according to Figure 1, consisting of three levels of controllers: three first-level controllers, two necessary for the power converters of the WECS generator and one for the pump motor, three secondlevel controllers, two necessary for the WECS and the one for the PS, and one third-level controller for the general operation of the entire system.

The frequency of the WECS exported power is controlled by the DFIG grid side controller described in Section 3.2.2, and the frequency of the pump's IM absorbed power is controlled by the IM controller described in Section 3.3.1.

\subsection{General System Controller}

The general system controller regulates the WECS power demand $P_{\text {wecsdem }}$ according to the pumping pressure reference expressed in pump head $H$. The controller is developed based on the first-order Tylor polynomial linearization of the affinity laws (20):

$$
H_{s}=H_{0}+\left(\omega_{p s s}-\omega_{p s 0}\right) \cdot(\dot{H})_{\omega p s 0} ;
$$

By substituting

$$
\Delta \omega_{p s}=\left(\omega_{p s s}-\omega_{p s 0}\right) \text { and } \Delta H=\left(H_{s}-H_{0}\right)
$$

in Equation (28), results in the following

$$
\begin{gathered}
\Delta H=\Delta \omega_{p s} \cdot(\dot{H})_{\omega p s 0}=\Delta \omega_{p s} \cdot \frac{2 \cdot H_{0}}{\omega_{0}} ; \Delta \omega_{p s}=\frac{\omega_{p s 0}}{2 \cdot H_{0}} \cdot \Delta H \\
P_{p s s}=P_{p s 0}+\left(\omega_{p s s}-\omega_{p s 0}\right) \cdot\left(\dot{P_{p s}}\right)_{\omega p s 0} ;
\end{gathered}
$$

By a similar substitution as in Equation (29), Equation (31) becomes:

$$
\Delta P_{p s}=\Delta \omega_{p s} \cdot\left(\dot{P_{p s}}\right)_{\omega p s 0}=\Delta \omega \cdot \frac{3 \cdot P_{p s 0}}{\omega_{0}}
$$

From Equations (30) and (32)

$$
\Delta P_{p s}=\frac{3 \cdot P_{p s 0}}{2 \cdot H_{0}} \cdot \Delta H
$$

The WECS power demand $P_{\text {wecsdem }}$ is calculated according to the following:

$$
P_{\text {wecsdem }}=\left\{\begin{array}{cc}
P_{p s 0} \cdot \eta_{0} & H_{s}<H_{0} \\
\left(\frac{3 \cdot P_{p s 0}}{2 \cdot H_{0}} \cdot \Delta H+P_{p s 0}\right) \cdot \eta_{s} & H_{s} \geq H_{0}
\end{array}\right.
$$




\subsection{WECS Controller}

The WECS controller was developed based on the combination between the first control level (DFIG including the rotor and grid side controllers) from reference $[15,17]$ with the second control level (WT controller) from reference [14], with several modifications to adapt the WECS power production to the pumping system operating point.

The first control level consists of two modulator controllers that regulate the convertors switch pulses to the desired reference values, to ensure proper and effective power generation.

\subsubsection{DFIG Rotor Side Controller}

The DFIG rotor side controller consists of a rotor flux-oriented vector controller that controls the modulator generating the rotor converter switch pulses necessary for maintaining the magnitudes of the generator (such as torque, active, and reactive power) close to their optimum values.

The DFIG rotor flux-oriented vector control regulates the $\mathrm{d}$-q rotor currents by using a regulator for each current component and is mainly performed according to reference [17] (p. 283) with several modifications.

The gains for the proportional-integral (PI) regulators for the current loops are calculated in Equations (35) and (36) according to the second-order system with two poles and one zero presented in reference [17] (p. 282).

$$
\begin{gathered}
k_{p r}=\frac{2 \cdot 100 \cdot\left(\sigma_{D F I G}\right)^{2} \cdot\left(L_{D F I G . r}\right)^{2}}{R_{D F I G . r}}-R_{D F I G . r} \\
k_{i r}=\frac{10000 \cdot\left(\sigma_{D F I G}\right)^{3} \cdot\left(L_{D F I G . r}\right)^{3}}{\left(R_{D F I G . r}\right)^{2}}
\end{gathered}
$$

where $k_{p r}$ is the proportional gain of the DFIG rotor side regulator, $k_{i r}$ is the integral gain of the DFIG rotor side regulator, $L_{D F I G . r}$ is the rotor inductance, $R_{D F I G . r}$ is the rotor resistance, and $\sigma_{D F I G}$ can be found in Equation (10).

\subsubsection{DFIG Grid Side Controller}

The DFIG grid side controller consists of a grid voltage-oriented vector controller that regulates the modulator generating the rotor converter switch pulses necessary for maintaining the magnitudes of the grid side converter (such as the reactive power and the DC bus voltage) close to their optimum values.

The DFIG grid voltage-oriented control regulates the voltage (Vbus) of the DC link (mainly formed by a capacitor) so that part of the WECS generated power can be delivered through the rotor. Therefore, by only maintaining the Vbus variable at a constant value, this active power flow through the converters is ensured, together with a guarantee that both grid and rotor side converters have the required DC voltage needed to work properly [15]. The DFIG grid voltage-oriented control is implemented according to reference [15] (p. 146), [20] (p. 178).

The gains for the proportional-integral (PI) regulators for the current loops are calculated in Equations (38) and (39) according to the closed-loop current expressions, from reference [24] (p. 180).

$$
s^{2} \cdot\left(L_{f}\right)+s \cdot\left(R_{f}+k_{p g}\right)+k_{i g} \equiv s^{2}+2 \cdot \xi_{1} \cdot \omega_{n 1} \cdot s+\left(\omega_{n 1}\right)^{2}
$$

From which results:

$$
\begin{gathered}
k_{p g}=2 \cdot L_{f} \cdot \xi_{1} \cdot \omega_{n 1}-R_{f} \\
k_{i g}=L_{f} \cdot\left(\omega_{n 1}\right)^{2}
\end{gathered}
$$

where $k_{p g}$ is the proportional gain or the DFIG grid side regulator, $k_{i g}$ is the integral gain of the DFIG gride side regulator, and $L_{f}$ is the grid side filter inductance; $R_{f}$ is the grid side 
filter resistance, and $\omega n 1$ and $\xi_{1}$ are the first natural frequency and damping ratio of the closed-loop system, respectively, Equation (37).

The second control level, called the WT controller, consists of two controllers-the generator torque controller and the blade pitch controller.

\subsubsection{WT Generator Torque Controller}

A WT generator-torque (partial load) controller, that maximizes the power capture below the rated operation point, while the blade pitch is kept constant at $0\left(\beta_{\text {ref }}=0^{\circ}\right)$ (the WT generator-torque controller was developed by combining $[1,13,15,25]$ ) can be represented as:

$$
T_{\text {gen.ctr }}\left(\omega_{\text {gen }}\right)=\left\{\begin{array}{cl}
0, & \omega_{\text {gens }} \leq \omega_{\text {cut.in }} \text { or } v_{\text {rot }}>v_{\text {cutout }} \\
a_{1-2} \cdot \omega_{\text {gen }}+b_{1-2}, & \omega_{\text {cut.in }}<\omega_{\text {gens }}<\omega_{\text {optimal }} \\
k_{\text {opt }} \cdot\left(\omega_{\text {gen }}\right)^{2}, & \omega_{\text {opt }} \leq \omega_{\text {gens }} \leq \omega_{m s} \\
a_{2-3} \cdot \omega_{\text {gen }}+b_{2-3}, & \omega_{m s}<\omega_{\text {gens }}<\omega_{\text {gen } 0} \\
\beta_{\text {ref }}=0^{\circ}
\end{array}\right.
$$

Equation (40) is taken into consideration when $P_{\text {wecsdem }} \geq P_{\text {wees } 0} A N D \omega_{\text {gens }}<\omega_{\text {gen } 0}$, where $v_{\text {rot }}$ is the average wind speed over the rotor; $v_{\text {cutout }}$ is the cutout wind speed over the rotor; $T_{\text {gen.ctr }}$ is the controller desired generator torque; $\omega_{\text {gen }}$ is the generator speed; $P_{\text {wecsdem }}$ the WECS demanded power; $P_{\text {weess }}$ the WECS actual power; $\eta_{g e n}$ the rated generator efficiency; $\omega_{\text {cut.in }}$ the generator angular velocity at cut-in wind speed; $\omega_{\text {optimal }}$ the generator angular velocity at optimal tip speed ratio; $\omega_{m s}$ the generator rotor mechanical speed at synchronous stator speed.; $\omega_{\text {gens }}$ the actual generator angular velocity; $\omega_{\text {gen } 0}$ the rated generator angular velocity; and $\beta_{\text {ref }}$ the reference pitch angle.

$a_{1-2}$ and $b_{1-2}$ represent the coefficients of the linear equation between regions 1 and 2 in Figure 4:

$$
\begin{aligned}
a_{1-2} & =\frac{k_{\text {opt }} \cdot\left(1.3 \cdot \omega_{\text {cut.in }}\right)^{2}}{0.3 \cdot \omega_{\text {cut.in }}} \\
b_{1-2} & =-a_{1-2} \cdot \omega_{\text {cut.in }} \\
\text { With } k_{\text {opt }}= & \frac{1}{2} \cdot \frac{R^{5}}{\left(\lambda_{\text {peak }}\right)^{3} \cdot N^{3}} \cdot \rho \cdot \pi \cdot C p_{\text {peak }}
\end{aligned}
$$

where $C p_{\text {peak }}$ is the power coefficient peak value when pitch angle $=0^{\circ}$ and $k_{\text {opt }}$ is the optimal constant that also corresponds to the optimal generator torque in Figure 4:

$$
\text { With } T_{\text {genoptimal }}=k_{\text {opt }} \cdot\left(\omega_{\text {gens }}\right)^{2}
$$

Similar to Equations (41) and (42), in Equations (45)-(46) $a_{2-3}$ and $b_{2-3}$ represent the coefficients of the linear equation between regions 2 and 3 in Figure 4:

$$
\begin{gathered}
a_{2-3}=\frac{T_{g e n 0}-k_{o p t} \cdot\left(\omega_{m s}\right)^{2}}{99 \% \cdot \omega_{g e n 0}-\omega_{m s}} \\
b_{2-3}=k_{o p t} \cdot\left(\omega_{m s}\right)^{2}-a_{2-3} \cdot \omega_{m s}
\end{gathered}
$$

Figure 4 shows the controller generator torque reference, $T_{\text {gen.ctrl }}$ in Equation (40), as a function of the filtered generator speed. 


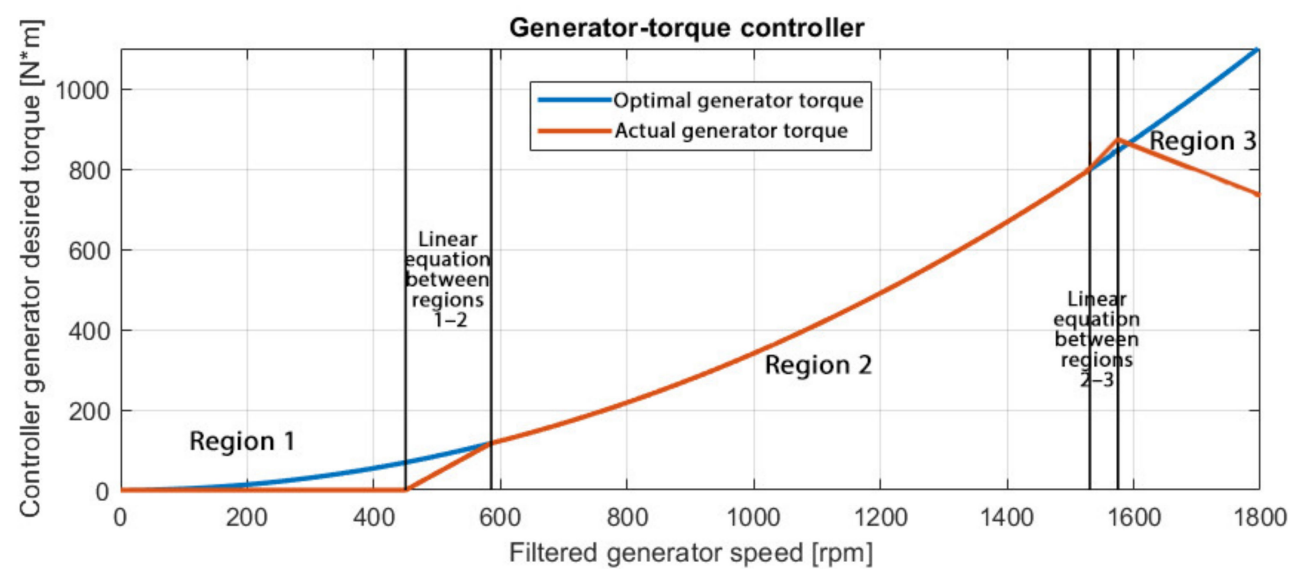

Figure 4. Generator-torque controller diagram.

\subsubsection{WT Blade Pitch Controller}

The second WT controller is a rotor-collective blade-pitch (full load) controller that starts its operation when the aerodynamic power is higher than the demanded power and has the goal to indirectly regulate the generator speed to the rated speed, and directly regulate the rotor speed by pitching the blades. Because the sensitivity (the first derivative) of the aerodynamic torque to the rotor-collective blade pitch varies nearly linearly with the blade-pitch angle [17], constant PI gains are not adequate for effective speed control and a linear gain correction with the same slope as the rotor torque sensitivity (a function of the blade-pitch angle) is implemented.

$$
\begin{aligned}
& K p_{\text {wecs }}(\beta)=K p_{\text {wecs }} \cdot G K(\beta) \\
& K i_{\text {wecs }}(\beta)=K i_{\text {wecs }} \cdot G K(\beta)
\end{aligned}
$$

where:

$K p_{\text {wees }}(\beta)$ and $K i_{\text {wecs }}(\beta)$ are the controller's proportional and integral gains, respectively, at $\beta$ pitch angle, and

$K p_{\text {wees }}$ and $K i_{\text {wecs }}$ are the base pitch controller proportional and integral gains, respectively, at the rated operation point.

$G K(\beta)=\frac{1}{1+\frac{\beta}{\beta_{k}}}$ is the linear gain correction factor, based on the blade-pitch angle according to reference [25], in which $\beta$ [in radians in this formula] is the pitch angle and $\beta k$ [radians/s] is the pitch angle where the pitch sensitivity has doubled.

The pitch angle where the rotor torque sensitivity as a function of blade-pitching angle has doubled $\left(\beta_{k}\right)$ is calculated from Equation (3), after being linearized with the Taylor expansion series:

$$
\begin{gathered}
2 \cdot T_{w t 0}=T_{w t 0}+\left.\frac{\partial T_{w t}}{\partial \beta}\right|_{\left(v_{r o t 0}, \omega_{w t 0}, \beta_{0}\right)} \cdot\left(\beta_{0}-\beta_{k}\right) \\
\beta_{k}=\beta_{0}-\frac{T_{w t 0}}{\left.\frac{\partial T_{w t 0}}{\partial \beta}\right|_{\left(v_{r o t}, \omega_{w t 0}, \beta_{0}\right)}}
\end{gathered}
$$

where: $T_{w t}$ is the rotor torque at linearization point ( $T_{w t 0}$ being the rated value); $\beta_{0}=0$ is the rated pitch angle in the rated operation point, $\beta k[\mathrm{rad} / \mathrm{s}]$ is the pitch angle where the rotor torque sensitivity has doubled, $v_{\text {rot } 0}$ is the average wind speed over the rotor, and $\omega_{w t 0}$ is the angular rotor velocity.

Figure 5 shows the wind turbine blade-pitch controller gain correction factor $[\mathrm{GK}(\beta)]$ and the gain scheduling law. 


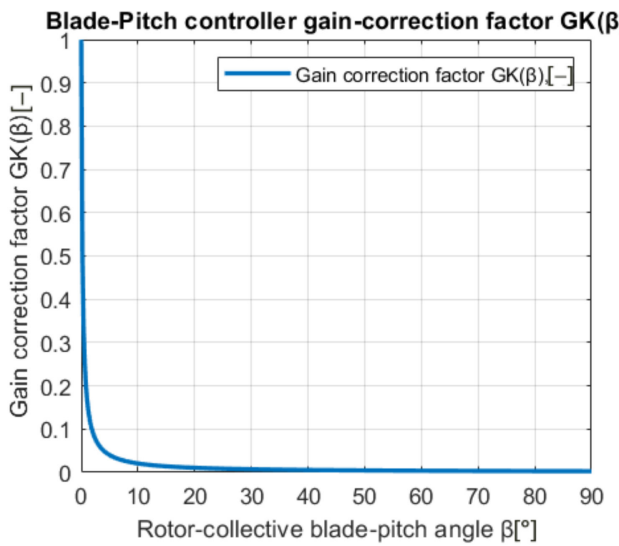

(a)

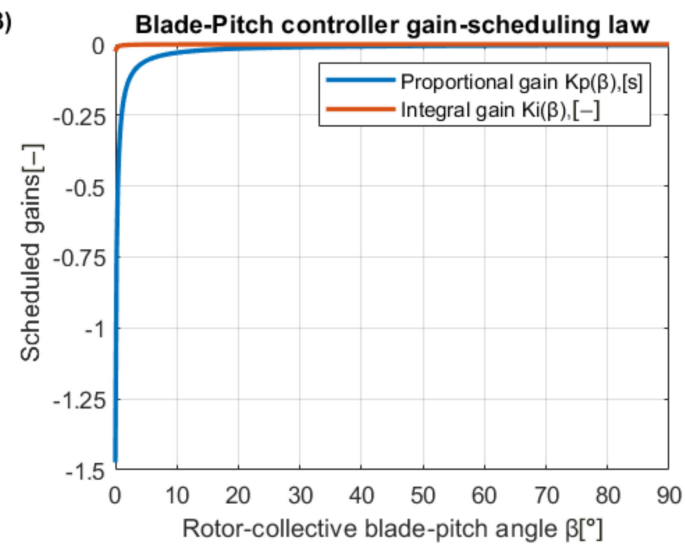

(b)

Figure 5. WT blade-pitch controller (a) gain correction factor GK $(\beta)$; (b) gain scheduling law.

By combining a blade-pitching angle PI closed-loop equation with the linear gain correction Equation (49), the final closed-loop equation is obtained:

$$
\begin{gathered}
T_{\text {gen.ctr }}\left(\omega_{\text {gens }}\right)=\frac{P_{\text {wees } 0}}{\omega_{\text {gens }} \cdot \eta_{\text {gen }}}, \\
\beta_{\text {ref }}=\frac{\beta_{k}}{\beta_{k}+\beta_{\text {ref }}} \cdot K p_{\text {wecs }} \cdot \omega_{\text {err }}+\frac{\beta_{k}}{\beta_{k}+\beta_{\text {ref }}} \cdot K i_{\text {wecs }} \cdot \int \omega_{\text {err }},
\end{gathered}
$$

Equation (51) is taken into consideration when $P_{\text {wecsdem }} \leq P_{\text {wecs } 0}$ OR $\omega_{\text {gens }} \geq \omega_{\text {gen } 0}$ where $\beta_{\text {ref }}$ is the reference pitch angle; $\beta \mathrm{k}$ is the pitch angle where the pitch sensitivity has doubled; $K p_{\text {wecs }}$ and $K i_{\text {weecs }}$ are the pitch controller proportional and integral gains, respectively, at the rated operation point; and $\omega_{\text {err }}=\omega_{\text {rated }}-\omega$ represents the difference between the rated and actual generator angular velocity.

In the blade-pitch controller, there is a conditional statement for setting as a reference for the upper limit of the blade-pitch angle when the wind speed in front of the rotor reaches the cutout wind speed.

\subsection{Pumping System Controller}

The PS controller was developed based on the combination of the first control level (IM controller) from reference [24] and the second control level (pump speed controller) from reference [26].

Because the pump system controller is in cascade with the WECS controller, the produced power by the WECS is passed to the PS controller, based on which the PI controlled error $\omega_{\text {pserr }}$ (the difference between the reference and current pump speed) is calculated using Equation (29):

$$
\omega_{\text {PSerr }}=\left\{\begin{array}{cl}
-\omega_{p s s} & P_{\text {wecs }}<P_{p s \min } \\
\frac{\omega_{p s 0}}{3 \cdot P_{p s 0}} \cdot\left(P_{\text {wecs }}-P_{p s s}\right) & P_{\text {wecs }} \geq P_{p s \min }
\end{array}\right.
$$

where $P_{p s \min }$ represents the minimum power required by the pump motor to work properly; in this particular case, for pumping the minimum flow required by the pump motor for cooling.

\subsubsection{IM Controller}

The IM motor controller uses a standard solution for current regulation in vectorcontrolled AC drives [24] (p. 59), called the synchronous PI current regulator, with two independent regulators, one for the $\mathrm{d}$ and one for the $\mathrm{q}$ axis. 
The synchronous PI current regulators are tuned using a second-order equivalent system presented in reference [24] (p. 61):

$$
\begin{gathered}
s^{2} \cdot\left(\sigma_{I M} \cdot L_{I M . s}\right)+s \cdot\left(R_{I M . s}+k_{p p s}\right)+k_{i p s} \equiv s^{2}+2 \cdot \xi_{2} \cdot \omega_{n 2} \cdot s+\left(\omega_{n 2}\right)^{2} \\
k_{p p s 1}=\sigma_{I M} \cdot L_{I M . s} \cdot 2 \cdot \xi_{2} \cdot \omega_{n 2}-R_{I M . s} \\
k_{i p s 1}=\sigma_{I M} \cdot L_{I M . s} \cdot\left(\omega_{n 2}\right)^{2} \\
\text { with } \sigma_{I M}=1-\frac{\left(L_{I M . m}\right)^{2}}{L_{I M . s} \cdot L_{I M . r}}, \xi_{2}=1, \omega_{n 2}=\frac{10}{\frac{\sigma_{I M} \cdot L_{I M . s}}{R_{I M . s}}}
\end{gathered}
$$

where $k_{p p s 1}$ represents the proportional gain of the IM motor PI controller; $k_{i p p s 1}$ represents the integral gain of the IM motor PI controller; $\omega_{\mathrm{n} 2}$ and $\xi_{2}$ are the first natural frequency and damping ratio, respectively, of the closed-loop system, Equation (53), and the most suitable double real poles of the closed-loop system $\left(-\omega_{n 2}\right)$ were identified by trial and error to be $\frac{10}{\frac{\sigma_{I M} \cdot L_{I M . s}}{R_{I M . s}}}$.

\subsubsection{Pump Speed Controller}

The speed control loop provides the frequency reference to the induction motor controller. The speed regulator is a PI type and is tuned taking into account the following second-order equivalent system:

$$
s^{2} \cdot\left(\frac{2 \cdot \pi}{p_{\text {motor }}} \cdot I_{p s}\right)+s \cdot k_{p p s 2}+k_{i p s 2}=s^{2}+2 \cdot \xi_{3} \cdot \omega_{n 3} \cdot s+\left(\omega_{n 3}\right)^{2}
$$

with

$$
\begin{aligned}
k_{p p s 2} & =\frac{2 \cdot \pi}{p_{\text {motor }}} \cdot I_{p s} \cdot 2 \cdot \xi_{3} \cdot \omega_{n 3} \\
k_{\text {ips } 2} & =\frac{2 \cdot \pi}{p_{\text {motor }}} \cdot I_{p s} \cdot\left(\omega_{n 3}\right)^{2}
\end{aligned}
$$

where $k_{p p s 2}$ represents the proportional gain of the PS speed controller; $k_{i p s 2}$ represents the integral gain of the PS speed controller; $\omega_{\mathrm{n} 3}$ and $\xi_{3}$ are the first natural frequency and damping ratio, respectively, of the closed-loop system in Equation (57).

\section{Simulation Results and Discussions}

Several simulations depicting different circumstances were conducted to determine how the presented control responds. The input parameters necessary for modeling, defining the controller, and running the simulation are presented in Table A1 of Appendix A. All the gains and parameters of the controller are presented in Table A2 of Appendix A. The scenario depicted in the current paper illustrates how the PS responds with an available power produced by a WECS during a wind speed ramp from 4 to $26 \mathrm{~m} / \mathrm{s}$ (the considered WECS operates under normal conditions and when the demanded power equals the rated power, in a wind speed ranging from 5 to $25 \mathrm{~m} / \mathrm{s}$ ). Figure 6 shows the blade-pitching angle operation of the WECS (when the demanded power equals the actual power, necessary for operating the pumping system at its rated power).

Figure 7 shows the response of the key parameters in the operation of the PS powered by the WECS. 


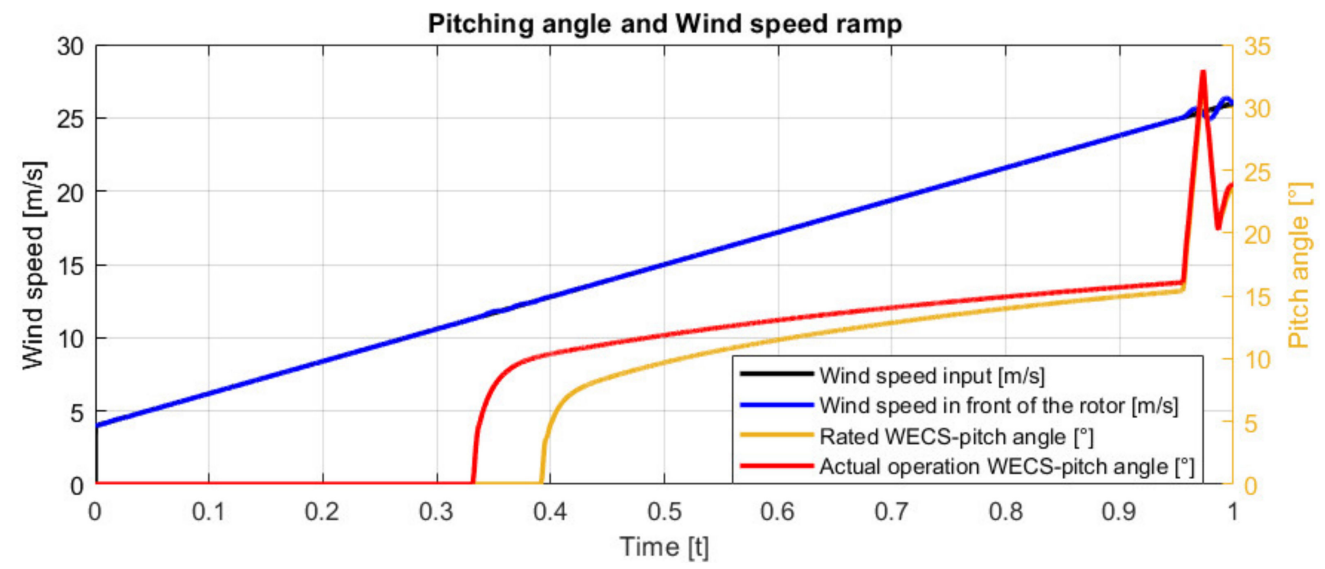

Figure 6. Pitch angle variation during the wind speed ramp.
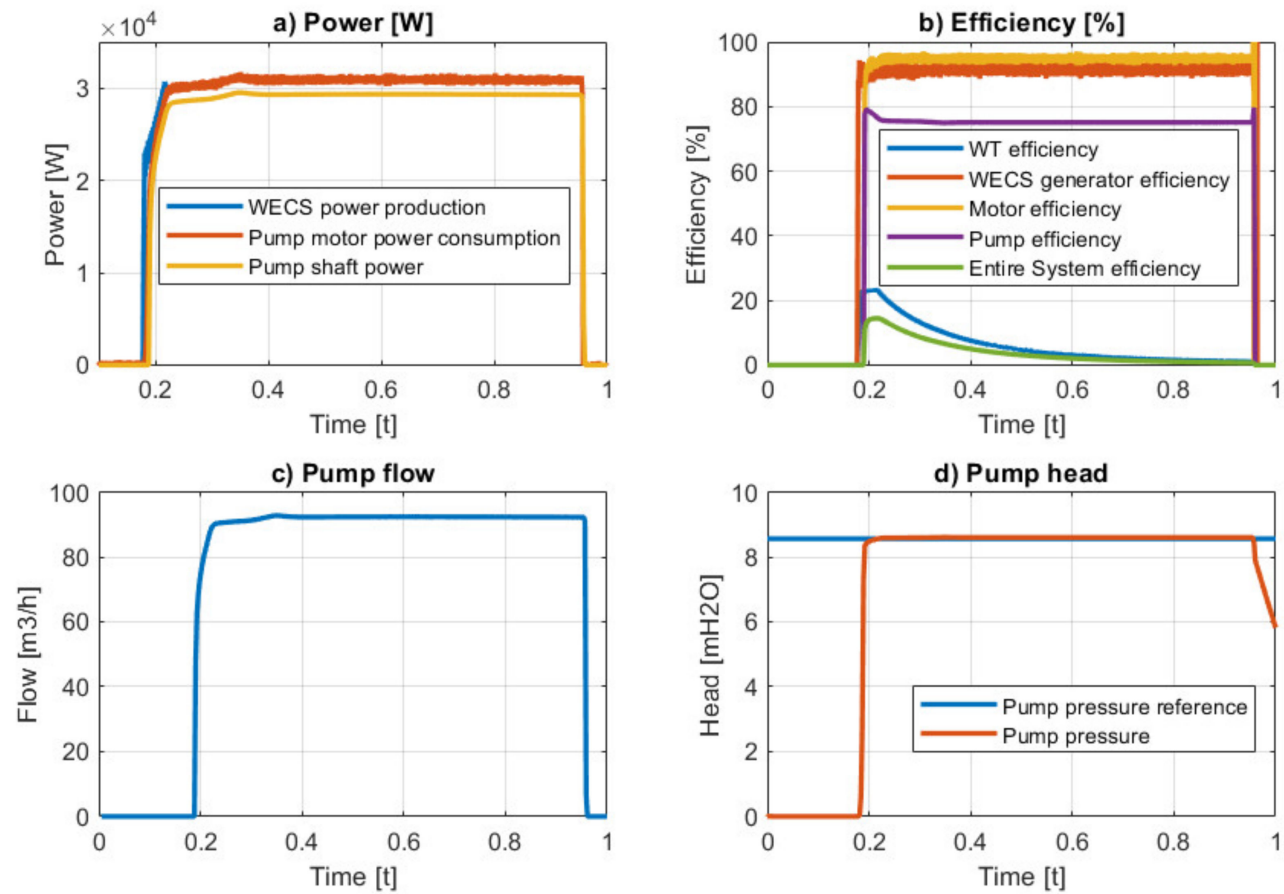

Figure 7. Simulation results: (a) WECS power production and PS power consumption; (b) efficiency of each subsystem in the PS powered by the WECS; (c) pump flow; (d) pump head including its reference.

Figure 7a shows the WECS theoretical produced power (blue), the pump, and motor power (red and yellow). This diagram illustrates the maximum power point tracking operating at partial load when the power consumption of the PS motor follows the WECS produced power received as a reference in cascade (time from 20 to $40 \mathrm{~s}$ ), and the pressure regulator (the PI controller that regulates the WECS power demand according to the pumping pressure reference) is operating at full-load (time from 40 to $115 \mathrm{~s}$ );

Figure $7 \mathrm{~b}$ shows the efficiencies of each subsystem integrated into the PS powered by the WECS (blue-wind turbine, red-WECS generator, yellow-pump motor efficiency, purple-pump efficiency, green-the entire system efficiency);

Figure 7c shows the flow pumped by the system, and Figure 7d shows the head of the pump and the pressure reference expressed in the pump head.

Figure 8 presents a comparison between the response of the same WECS (more details can be found in reference [27]), operating when the demanded power is equal to the rated power (as a WECS operating in a wind farm with the purpose of injecting all the energy 
into the grid), and operating when the demanded power is the power required by the pump for its rated operation (the rated power of the pump has to be lower than the rated power of the WECS).
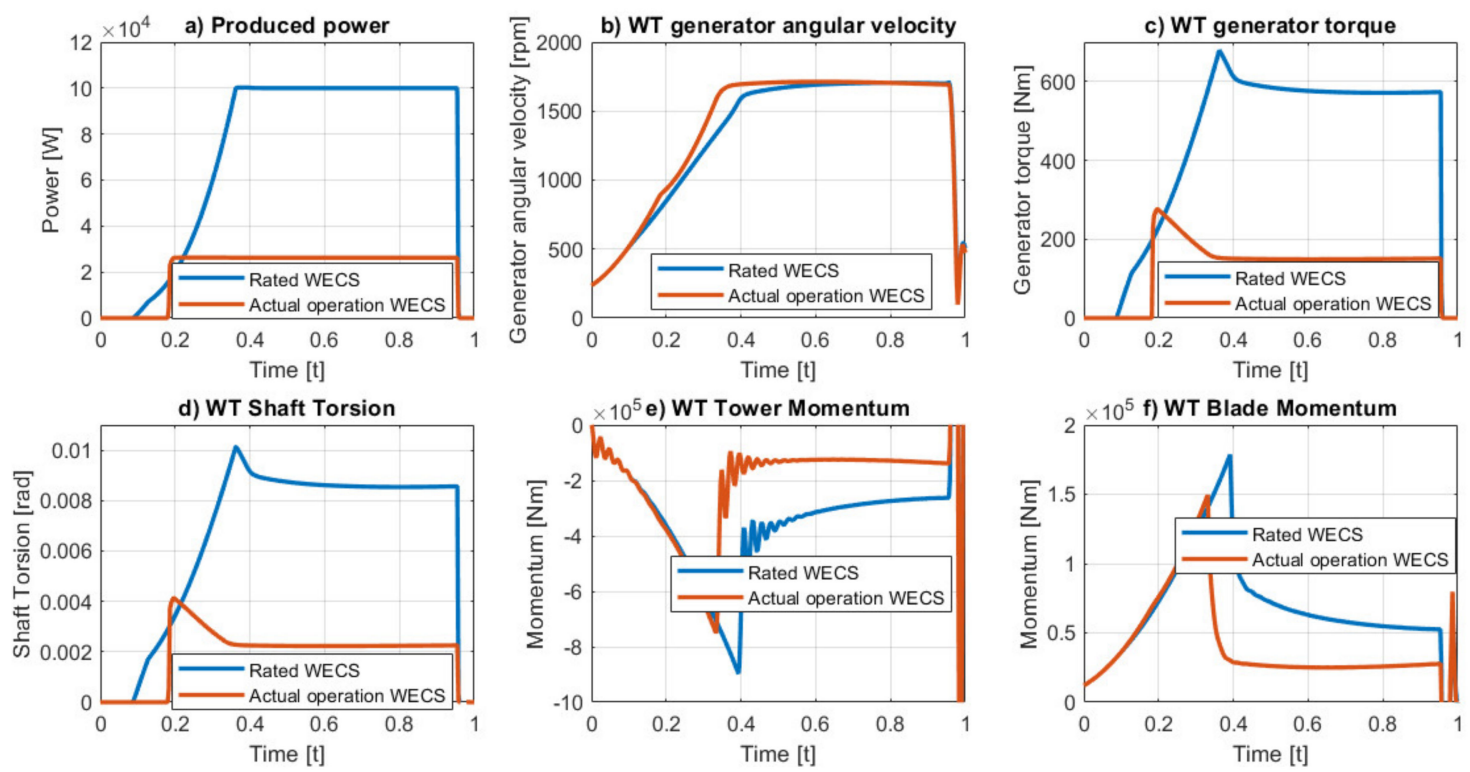

Figure 8. Rated vs actual operation of the WECS comparison: (a) power production comparison; (b) generator angular velocity comparison; (c) generator torque comparison; (d) drive train torsion comparison; (e) tower momentum comparison; (f) blade momentum comparison.

Figure 8a presents the power produced by the WECS when the demanded power is equal to the rated power of the WECS (blue), and the rated power of the PS (red). Figure 8b shows the WECS generator angular velocity in both operating conditions presented above. It can be observed that, when the demanded power from the WECS is lower than the rated power, the WECS generator angular velocity reaches its nominal point faster.

In Figure 8c, it can be observed that the WECS power is derated mainly by derating the WT and generator torque in order to reduce the loads taken by the drive train (WT and WECS generator torques are adapted to the motor power). This fact is also confirmed by Figure $8 \mathrm{~d}$, where it can be seen that the torsion of the drive shaft is reduced proportionally to the derating power.

Figure 8e,f shows that how the proposed control strategy for the PS powered by a WECS also considers the loads of the WECS, as the tower and blades moments are reduced proportionally with the WECS power derated to the necessary power required by the PS for its rated operation.

\section{Conclusions}

This paper shows the application of leading-edge technology within the area of an irrigation PS powered by a pitching WECS, by presenting an advanced dynamic model of the entire system in the first, a system control strategy, and, finally, the simulation results.

The advanced dynamic model developed in this paper includes the main components of a WECS (a WT including pitchable blades and their actuator, its drive train and tower, and a DFIG together with its power converter) and of an irrigation PS (a centrifugal pump, an IM with its power converter, and an irrigation network with a pressure transducer).

The implemented system control strategy is based on local controllers distributed on three levels: a general controller that regulates the WECS power demand according to the pumping pressure reference; three second-level controllers; two necessary for controlling the WT generator torque and speed, and one for controlling the pump speed; and three 
first-level controllers-two for controlling the DFIG power converters of the WECS and one for controlling the IM power converter of the pump.

Finally, the results depicting the simulations of a general operation of the system covering its transition through the entire operation range showed the good performance and effectiveness of the developed control system strategy. The simulation results presented in Figures 7 and 8 confirm the contribution of the current work in controlling a PS powered by a WECS, the regulation of the pump speed so that the PS consumption power tracks the WECS produced power (Equation (52)) at partial load, and the regulation of the WECS power demand to control the head pressure of the PS (Equation (34)) at full load. The simulation results illustrated in Figure 8 show that, at full load operation, the WECS produces only the power necessary for the rated operation of the PS, in order to avoid unnecessary loading of the WECS components.

The main contribution of the current work compared to other related work [7-10] consists of integrating a commercial WECS, without altering its hardware or controller, into an existing pumping system. The main reason why most WECS manufacturers are not open to adjusting their current control strategies for a full and perfect integration within a PS is because such an adjustment represents a significant cost, and the WECS manufacturers do not believe the current market for a PS that requires a WECS is large enough to pay this cost. Nevertheless, the unintrusive proposed control strategy system and the promising simulations results indicate the possibility for the application of the proposed scheme to be set up for online implementation.

Author Contributions: Conceptualization, D.B., O.P. and C.H.; methodology, D.B., O.P. and C.H.; software, D.B., O.P. and C.H.; validation, D.B., O.P. and C.H.; formal analysis, D.B., O.P. and C.H.; investigation, D.B., O.P. and C.H.; resources, D.B., O.P. and C.H.; data curation, D.B., O.P. and C.H.; writing-original draft preparation, D.B., O.P. and C.H.; writing-review and editing, D.B., O.P. and C.H.; visualization, D.B., O.P. and C.H.; supervision, D.B., O.P. and C.H.; project administration, D.B., O.P. and C.H.; funding acquisition, D.B., O.P. and C.H. All authors have read and agreed to the published version of the manuscript.

Funding: This research received no external funding.

Institutional Review Board Statement: Not applicable.

Informed Consent Statement: Not applicable.

Conflicts of Interest: The authors declare no conflict of interest.

\section{Appendix A}

Table A1 presents the input parameters necessary for modeling, defining the controller, and running the simulation.

Table A1. Necessary parameters for modeling, defining. the controller and running the simulations [22,27].

\begin{tabular}{cccc}
\hline Component & Notation & Parameter Description & Value \\
\hline & $v$ & Wind speed in front of the WT rotor & 4 to $26[\mathrm{~m} / \mathrm{s}]$ \\
& $v_{\text {rot }}$ & Average wind speed acting on the WT rotor & 4 to $26[\mathrm{~m} / \mathrm{s}]$ \\
& $v_{\text {cut.in }}$ & Cut-in wind speed in front of the WT rotor & $5[\mathrm{~m} / \mathrm{s}]$ \\
& $v_{\text {rated }}$ & Rated wind speed in front of the WT rotor & $13[\mathrm{~m} / \mathrm{s}]$ \\
WECS & $v_{\text {cut.out }}$ & Cut out wind speed in front of the WT rotor & $25[\mathrm{~m} / \mathrm{s}]$ \\
WT & $v$ & Wind speed in front of the WT rotor & 4 to $26[\mathrm{~m} / \mathrm{s}]$ \\
& $\lambda$ & WT rotor tip speed ratio & $3.923[\mathrm{rad} / \mathrm{s}]$ \\
& $R$ & WT rotor radius & $10.5[\mathrm{~m}]$ \\
& $\omega_{w t}$ & Nominal WT rotor angular velocity & $4.857[\mathrm{rad} / \mathrm{s}]$ \\
& $T_{w t}$ & Nominal WT rotor torque & $20,588[\mathrm{~N} \cdot \mathrm{m}]$ \\
\hline
\end{tabular}


Table A1. Cont.

\begin{tabular}{|c|c|c|c|}
\hline Component & Notation & Parameter Description & Value \\
\hline \multirow{5}{*}{$\begin{array}{c}\text { WECS } \\
\text { WT }\end{array}$} & $\rho_{\text {air }}$ & Average air density over the WT rotor & $1.2231\left[\mathrm{~kg} / \mathrm{m}^{3}\right]$ \\
\hline & $C_{p}$ & Power coefficient lookup table [27] & {$[-]$} \\
\hline & $C_{T}$ & Thrust coefficient lookup table [27] & {$[-]$} \\
\hline & $\beta$ & Nominal blade pitching angle & $0\left[^{\circ}\right]$ \\
\hline & $H_{h u b}$ & WT hub height & $38[\mathrm{~m}]$ \\
\hline \multirow{4}{*}{$\begin{array}{l}\text { WECS } \\
\text { Drive } \\
\text { Train }\end{array}$} & $I_{w t}$ & WT rotor inertia & $115,762\left[\mathrm{~kg} \cdot \mathrm{m}^{2}\right]$ \\
\hline & $K_{\text {shaft }}$ & WT low-speed shaft spring constant & $\begin{array}{c}2,208,535 \\
{[\mathrm{~N} \cdot \mathrm{m} / \mathrm{rad}]}\end{array}$ \\
\hline & $B_{\text {sfhat }}$ & WT low-speed shaft damping constant & $15,820[\mathrm{~kg} / \mathrm{s}]$ \\
\hline & $N$ & Gear ratio & $33[-]$ \\
\hline \multirow{14}{*}{$\begin{array}{l}\text { WECS } \\
\text { DFIG }\end{array}$} & $I_{\text {gen }}$ & DFIG inertia & $10.682\left[\mathrm{~kg} \cdot \mathrm{m}^{2}\right]$ \\
\hline & $p_{\text {gen }}$ & DFIG poles & $4[-]$ \\
\hline & $u_{d f i g}$ & DFIG stator/rotor turns ratio & $1[-]$ \\
\hline & $f_{d f i g}$ & DFIG rated frequency & $50[\mathrm{~Hz}]$ \\
\hline & $V_{d f i g}$ & DFIG rated voltage & $400[\mathrm{~V}]$ \\
\hline & $I_{\text {dfig }}$ & DFIG rated current & $145[\mathrm{~A}]$ \\
\hline & $\omega_{\text {gen }}$ & DFIG rated angular velocity & $1500[\mathrm{rpm}]$ \\
\hline & $R_{\text {dfig.S }}$ & DFIG stator resistance & $0.08[\Omega]$ \\
\hline & $R_{\text {dfig.R }}$ & DFIG rotor resistance & $0.008[\Omega]$ \\
\hline & $L_{\text {dfig.m }}$ & DFIG magnetizing induction & $0.007[\mathrm{H}]$ \\
\hline & $L_{d f i g . R}$ & DFIG rotor inductance & $0.074[\mathrm{H}]$ \\
\hline & $L_{d f i g . S}$ & DFIG stator inductance & $0.074[\mathrm{H}]$ \\
\hline & $V_{b u s}$ & DC bus voltage referred to the DFIG stator & $690[\mathrm{~V}]$ \\
\hline & $P_{\text {wecs }}$ & DFIG rated power & $100[\mathrm{~kW}]$ \\
\hline \multirow{4}{*}{$\begin{array}{l}\text { WECS } \\
\text { Tower }\end{array}$} & $m_{\text {wecs }}$ & WECS mass & 21 [tons] \\
\hline & $H_{\text {tow }}$ & Tower height & $35[\mathrm{~m}]$ \\
\hline & $\zeta_{\text {tow }}$ & Tower damping ratio & $0.08[-]$ \\
\hline & $f_{\text {ntow }}$ & Tower first eigenfrequency & $0.35[\mathrm{~Hz}]$ \\
\hline \multirow{4}{*}{$\begin{array}{l}\text { WECS } \\
\text { Pitch } \\
\text { Actuator }\end{array}$} & $\tau_{\beta}$ & Pitch actuator time constant & $0.1[\mathrm{~s}]$ \\
\hline & $\lambda_{\beta}$ & Pitch actuator delay & $0.1[\mathrm{~s}]$ \\
\hline & $K_{\beta}$ & Proportional gain of the Pitch regulator & $10[-]$ \\
\hline & $\beta_{\text {ref }}$ & Pitch angle reference & $0\left[^{\circ}\right]$ \\
\hline \multirow{12}{*}{$\begin{array}{l}\text { PS } \\
\text { IM }\end{array}$} & $P_{I M}$ & IM rated power & $51[\mathrm{~kW}]$ \\
\hline & $p_{I M}$ & IM poles & $2[-]$ \\
\hline & $u_{I M}$ & IM stator/rotor turns ratio & $1[-]$ \\
\hline & $f_{d f i g}$ & IM rated frequency & $50[\mathrm{~Hz}]$ \\
\hline & $V_{d f i g}$ & IM rated voltage & $400[\mathrm{~V}]$ \\
\hline & $I_{\text {dfig }}$ & IM rated current & $101[\mathrm{~A}]$ \\
\hline & $\omega_{I M}$ & IM rated angular velocity & 2910 [rpm] \\
\hline & $R_{i m . s}$ & IM stator resistance & $0.095[\Omega]$ \\
\hline & $R_{i m . r}$ & IM rotor resistance & $0.063[\Omega]$ \\
\hline & $L_{i m . m}$ & IM magnetizing induction & $0.032[\mathrm{H}]$ \\
\hline & $L_{i m . r}$ & IM rotor inductance & $0.034[\mathrm{H}]$ \\
\hline & $L_{i m . s}$ & IM stator inductance & $0.034[\mathrm{H}]$ \\
\hline \multirow{9}{*}{$\begin{array}{c}\text { PS } \\
\text { Centrifugal } \\
\text { Pump }\end{array}$} & $P_{\text {dem }}$ & Nominal power demanded by PS to WECS & $32.357[\mathrm{~kW}]$ \\
\hline & $P_{p s}$ & Nominal PS power & $26.2[\mathrm{~kW}]$ \\
\hline & $\omega_{P S}$ & Pump nominal angular velocity & $2400[\mathrm{rpm}]$ \\
\hline & $A$ & Pump characteristic curve 1 st coefficient & $185.212[\mathrm{~m}]$ \\
\hline & $B$ & Pump characteristic curve 2 nd coefficient & $0.261\left[\mathrm{~h} / \mathrm{m}^{2}\right]$ \\
\hline & C & Pump characteristic curve 3 rd coefficient & $-0.008\left[\mathrm{~h}^{2} / \mathrm{m}^{5}\right]$ \\
\hline & $D$ & Pump efficiency curve 1st coefficient & $1.8274\left[\mathrm{~h} / \mathrm{m}^{3}\right]$ \\
\hline & $E$ & Pump efficiency curve 2nd coefficient & $\begin{array}{l}-0.0104 \\
{\left[\mathrm{~h}^{2} / \mathrm{m}^{6}\right]}\end{array}$ \\
\hline & $H_{0}$ & Nominal pump operating head & $87.312[\mathrm{~m}]$ \\
\hline
\end{tabular}


Table A1. Cont.

\begin{tabular}{cccc}
\hline Component & Notation & Parameter Description & Value \\
\hline PS & $Q_{0}$ & Nominal pump operating flow & $86.56\left[\mathrm{~m}^{3} / \mathrm{h}\right]$ \\
Centrifugal & $\eta_{0}$ & Nominal pump efficiency & $0.81[-]$ \\
Pump & $k$ & Head loss coefficient & $0.00395\left[\mathrm{~h}^{2} / \mathrm{m}^{5}\right]$ \\
& $H g$ & Static head & $80.5[\mathrm{~m}]$ \\
\hline
\end{tabular}

Table A2 presents the parameters and gains of each local controller.

Table A2. Calculated controller parameters.

\begin{tabular}{|c|c|c|c|}
\hline Local Controller & Notation & Parameter Description & Value \\
\hline WECS & $k_{p r}$ & P gain of the DFIG rotor side regulator & $0.0635[-]$ \\
\hline DFIG rotor side controller & $k_{i r}$ & I gain of the DFIG rotor side regulator & $0.635[-]$ \\
\hline WECS & $k_{p g}$ & P gain of the DFIG grid side regulator & $0.002[-]$ \\
\hline DFIG grid side controller & $k_{i g}$ & I gain of the DFIG grid side regulator & $-0.002[-]$ \\
\hline \multirow{5}{*}{$\begin{array}{l}\text { WECS } \\
\text { WT generator torque } \\
\text { controller }\end{array}$} & $k_{o p t}$ & \multirow{2}{*}{$\begin{array}{c}\text { Optimal generator constant } \\
\text { 1st linear coefficient Equations (1) } \\
\text { and (2) region }\end{array}$} & $0.0314[-]$ \\
\hline & $a_{1-2}$ & & $8.34[-]$ \\
\hline & $b_{1-2}$ & $\begin{array}{l}\text { 2nd linear coefficient Equations (1) } \\
\text { and (2) region }\end{array}$ & $-393.174[-]$ \\
\hline & $a_{2-3}$ & $\begin{array}{c}\text { 1st linear coefficient Equations (2) } \\
\text { and (3) region }\end{array}$ & $34.823[-]$ \\
\hline & $b_{2-3}$ & $\begin{array}{l}\text { 2nd linear coefficient Equations (2) } \\
\text { and (3) region }\end{array}$ & $\begin{array}{c}-4889.242 \\
{[-]}\end{array}$ \\
\hline \multirow{2}{*}{$\begin{array}{c}\text { WECS } \\
\text { WT blade pitch controller }\end{array}$} & $K p_{\text {wecs }}$ & $\begin{array}{l}\text { Pitch controller } \mathrm{P} \text { gain at the rated } \\
\text { point }\end{array}$ & $-0.7395[-]$ \\
\hline & $K i_{\text {wec }}$ & $\begin{array}{l}\text { Pitch controller I gain at the rated } \\
\text { point }\end{array}$ & $-0.0129[-]$ \\
\hline \multirow{2}{*}{ PS IM controller } & $k_{p p s 1}$ & P gain of the PS IM controller & $120[-]$ \\
\hline & $k_{i p s 1}$ & I gain of the PS IM controller & $12,000[-]$ \\
\hline \multirow{2}{*}{ PS Pump speed controller } & $k_{p p s 2}$ & P gain of the PS pump speed controller & $1[-]$ \\
\hline & $k_{i p s 2}$ & I gain of the PS pump speed controller & $1.2[-]$ \\
\hline
\end{tabular}

\section{References}

1. Stoyanov, L.; Bachev, I.; Zarkov, Z.; Lazarov, V.; Notton, G. Multivariate Analysis of a Wind-PV-Based Water Pumping Hybrid System for Irrigation Purposes. Energies 2021, 14, 3231. [CrossRef]

2. Ursachi, A.; Bordeasu, D. Smart Grid Simulator, World Academy of Science, Engineering and Technology. Int. J. Civ. Archit. Sci. Eng. 2014, 8, 488-491. [CrossRef]

3. Ronad, B.F.; Jangamshetti, S.H. Optimal cost analysis of wind-solar hybrid system powered AC and DC irrigation pumps using HOMER. In Proceedings of the 2015 International Conference on Renewable Energy Research and Applications (ICRERA), Palermo, Italy, 22-25 November 2015; Volume 5, pp. 1038-1042. [CrossRef]

4. Sarasúa, J.I.; Martínez-Lucas, G.; Platero, C.A.; Sánchez-Fernández, J.Á. Dual Frequency Regulation in Pumping Mode in a Wind-Hydro Isolated System. Energies 2018, 11, 2865. [CrossRef]

5. Jamii, J.; Mimouni, F. Model of wind turbine-pumped storage hydro plant. In Proceedings of the 2018 9th International Renewable Energy Congress (IREC), Hammamet, Tunisia, 20-22 March 2018; pp. 1-6. [CrossRef]

6. Li, H.; Zheng, C.; Lv, S.; Liu, S.; Huo, C. Research on optimal capacity of wind power based on coordination with pumped storage power. In Proceedings of the 2016 IEEE PES Asia-Pacific Power and Energy Engineering Conference (APPEEC), Xi'an, China, 25-28 October 2016; pp. 1214-1218. [CrossRef]

7. Ouchbel, T.; Zouggar, S.; Elhafyani, M.L.; Seddik, M.; Oukili, M.; Aziz, A.; Kadda, F.Z. Power maximization of an asynchronous wind turbine with a variable speed feeding a centrifugal pump. Energy Convers. Manag. 2014, 78, 976-984. [CrossRef]

8. Barara, M.; Bennassar, A.; Abbou, A.; Akherraz, M.; Bossoufi, B. Advanced Control of Wind Electric Pumping System for Isolated Areas Application. Int. J. Power Electron. Drive Syst. 2014, 4, 567-577. [CrossRef] 
9. Zeddini, M.A.; Pusca, R.; Sakly, A.; Mimouni, M.F. MPPT control of Wind Pumping Plant Using Induction Generator. In Proceedings of the 14th International conference on Sciences and Techniques of Automatic Control \& Computer Engineering STA, Sousse, Tunisia, 20-22 December 2013; pp. 438-442.

10. Harrouz, A.; Dahbi, A.; Harrouz, O.; Benatiallah, A. Control of wind turbine based of PMSG connected to water pumping system in South of Algeria. In Proceedings of the 3rd International Symposium on Environmental Friendly Energies and Applications (EFEA), Paris, France, 19-21 November 2014; pp. 22-25. [CrossRef]

11. Hammerum, H. A Fatigue Approach to Wind Turbine Control; Technical University of Denmark: Kongens Lyngby, Denmark, 2006; pp. 5-22.

12. Hammerum, H.; Brath, P.; Poulsen, N.K. A fatigue approach to wind turbine control. J. Phys. Conf. Ser. 2007, 75, 012081. [CrossRef]

13. Zhang, C.; Wang, L.; Li, H. Experiments and Simulation on a Late-Model Wind-Motor Hybrid Pumping Unit. Energies 2020, 13, 994. [CrossRef]

14. Grunnet, J.D.; Soltani, M.N.; Knudsen, T.; Kragelund, M.N.; Bak, T. Aeolus Toolbox for Dynamics Wind Farm Model, Simulation and Control. In Proceedings of the European Wind Energy Conference and Exhibition, EWEC 2010: Conference Proceedings, Warszawa, Poland, 20-23 April 2010; pp. 3119-3129.

15. Abad, G.; López, J.; Rodríguez, M.A.; Marroyo, L.; Iwanski, G. Doubly Fed Induction Machine: Modeling and Control for Wind Energy Generation; John Wiley \& Sons: Hoboken, NJ, USA, 2011; pp. 155-238.

16. Haţiegan, C.; Chioncel1, C.P.; Răduca, E.; Popescu, C.; Pădureanu, I.; Jurcu, M.R.; Bordeaşu, D.; Trocaru, S.; Dilertea, F.; Bădescu, O.; et al. Determining the operating performance through electrical measurements of a hydro generator. IOP Conf. Ser. Mater. Sci. Eng. 2017, 163, 012031. [CrossRef]

17. Abu-Rub, H.; Malinowski, M.; Al-Haddad, K. Power Electronics for Renewable Energy Systems, Transportation and Industrial Applications; IEEE Press and John Wiley \& Sons Ltd.: Chichester, UK, 2014; pp. 277-356.

18. Janevska, G.; Bitola, R.M. Mathematical Modeling of Pump System. Electron. Int. Interdiscip. Conf. $2013,2,455-458$.

19. Yang, Z.; Soleiman, K.; Løhndorf, B. Energy Efficient Pump Control for an Offshore Oil Processing System. IFAC Proc. Vol. 2012, 45, 257-262. [CrossRef]

20. Sârbu, I.; Borza, I. Energetic optimization of water pumping in distribution systems. Period. Polytech. Ser. Mech. Eng. 1998, 42, 141-152.

21. White, F.M. Chapter 11 Turbomachinery. In Fluid Mechanics, 7th ed.; McGraw-Hill: New York, NY, USA, $2011 ;$ pp. 776-777.

22. Caprari, Submersible Electric Pump E8P95/7ZC+MAC870-8V Technical Data Sheet. 2019. Available online: https://ipump. caprarinet.net/ (accessed on 9 October 2021).

23. Li, W.; Ji, L.; Shi, W.; Zhou, L.; Chang, H.; Agarwal, R.K. Expansion of High Efficiency Region of Wind Energy Centrifugal Pump Based on Factorial Experiment Design and Computational Fluid Dynamics. Energies 2020, 13, 483. [CrossRef]

24. Abad, G. Power Electronics and Electric Drives for Traction Applications; John Wiley \& Sons: Chichester, UK, 2017; pp. 37-98, 149-185.

25. Jonkman, J.; Butterfield, S.; Musial, W.; Scott, G. Definition of a 5-MW Reference Wind Turbine for Offshore System Development; National Renewable Energy Laboratory: Golden, CO, USA, 2009; pp. 17-27.

26. Sul, S. Control of Electric Machine Drive Systems; John Wiley \& Sons: Hoboken, NJ, USA, 2011; pp. 92-96, $236-243$.

27. Fuhrländer, F.L. Fuhrländer FL 100 kW Wind Turbine Technical Data Sheet. 2021. Available online: https://en.wind-turbinemodels.com/turbines /279-fuhrlaender-fl-100-astos / (accessed on 9 October 2021). 